WAPD-TM-1429

DOE Research and Development Report

ARC - Weld Pool Interactions

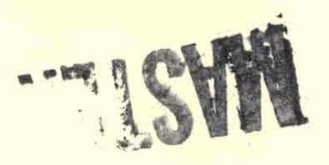

ISth

S. S. Glickstein

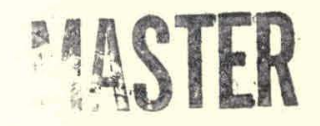

Bettis Atomic Power Laboratory

West Mifflin. Pennsylvania 15122

\title{
August 1978
}

Prepared for the

U.S. Department of Energy 


\section{DISCLAIMER}

This report was prepared as an account of work sponsored by an agency of the United States Government. Neither the United States Government nor any agency Thereof, nor any of their employees, makes any warranty, express or implied, or assumes any legal liability or responsibility for the accuracy, completeness, or usefulness of any information, apparatus, product, or process disclosed, or represents that its use would not infringe privately owned rights. Reference herein to any specific commercial product, process, or service by trade name, trademark, manufacturer, or otherwise does not necessarily constitute or imply its endorsement, recommendation, or favoring by the United States Government or any agency thereof. The views and opinions of authors expressed herein do not necessarily state or reflect those of the United States Government or any agency thereof. 


\section{DISCLAIMER}

Portions of this document may be illegible in electronic image products. Images are produced from the best available original document. 
Westinghouse Electric Corporation

Belts Atomic Power Laboratory

Box 79

West Muffin Pernsyivatia 1512

U.S. Department of Energy Technical Information Center

P.O. Box 62

Oak Ridge, Tennessee 37830

Gentlemen:

Transmitted herewith are copies of the document referenced below.

Document Number - WAPD-TM-1429

Distribution Category - UC-25 Special External

Number of Copies - .30

Classification - Unclassified.

Distribution is to be made by DOE -TIC to the following:

DOE Library, Washington

Ames Laboratory (DOE)

Argonne National Laboratory (DOF)

Atomics International (DOE)

Babcock and Wilcox Company (DOE)

Battelle Memorial Institute, Director (DOE)

Brookhaven National Laboratory (DOE)

Bureau of Mines, Albany (Int)

Combustion Engineering, Inc. (DOE)

Du Pant Company, Aiken (DOE)

$E G$ and $G$ Incorporated, Idaho (DOE)

Electric Power Res. Inst. (HQAP)

General Atomic Company (DOE)

General Electric Company, San Jose (DOE)

Lawrence Liver mure Laburalury. (DOE)

Less Alamo Scientific Laboratory (DOE)

IRC Library

Oak Ridge National Laboratory (DOE)

Westinghouse National Laboratory (DOE)

Westinghouse Electric Corporation (DOE)

Westinghouse Hanford Company (DOE)

IUE-TIC

Please advise us if you have any questions about this document.

Very truly yours,
May force
(Mrs.) Toryorionise razes

$M L F / v f$

(Mrs.) Mabyorionise Froze

Enclosure 
No, of Copies

DOE Library, Washington

Ames Laboratory (DOE)

Argonne National Laboratory (DOE)

1

Atomics International (DOE)

Babcock and Wilcox Company (DOR)

Battelle Memorial. Inst 1tute, Director (DOB)

Brookhaven National Laboratory (DOE)

Bureau of Mines, Albany (INT)

Combustion Bngineering, Inc. (DOE)

Du Pont Company, Alken (DOE)

BG and G Incorporated, Idaho (DOR)

Blectric Power Res. Inst. (HQAP)

General Atomic Company (DOE)

General Blectric Company, San Jose (DOE)

Lawrence Livermore Laboratory (DOE)

I08 Alamos Scientific Laboratory'(DOE)

NRC Library

Oak RIdge National Laboratory (DOE)

Westinghouse National Laboratory (DOE)

Westinghouse Blectric Corporation (DOE)

Westinghouse Hanford Company (DOE)

1

2

2

1

1

1

1

1

2

2

1

1

1

1

2

1

3

2.

2

2

DOQE-TIC

3

TOTAL 
ARC-WELD POOL INTERACTIONS

S. S. Glickstein

$E X-76-C-11-0014$

Contract No. EY-76-C-11-0014

August 1978

\author{
Printed in the United States of America \\ Available from the \\ National Technical Information Service \\ U. S. Department of Commerce \\ 5285 Port Royal Road \\ Springfield, Virginia 22151
}

\title{
NOTE
}

This document is an interim memorandum prepared primarily for internal reference and does not represent a final expression of the opinion of Westinghouse. When this memorandum is distributed externally, it is with the express understanding that Westinghouse makes no representation as to completeness, accuracy, or usability of information contained therein.

BETTIS ATOMIC POWER IABORATORY

WEST MIPFLIN, PENNSYLVANIA 15122

Operated for the U.S.Department of Energy

by Westinghouse Electric Corporat:--

This

This report was prepared as an account of work United States the United States Govemment. Neither the Energy, nor any the United States Department of contractors, subcontractors, or their, nor any of their any warranty, express or imptied, or aspumes, makes liability or responsibity for the ac or asumes any legal or use futness of any infor the accuracy, completeness process disces a dor process disclosed, or represents that its use would nol
infringe privately owned rights. 


\section{NOTICE}

This report was prepared as an account of work sponsored by the United States Guverńment. Neither the United States, nor the United States Department of Energy, nor any of their employees, nor any of their contractors, subcontractors, or their employees, makes any warranty, exprodo or implicd, or assumes any legal liability or responsibility for the accuracy, completeness or usefulness of any information, apparatus, product or process disclosed, or represents that its use would not infringe privately owned rights. 


\author{
ARC-WELD POOL INTERACTIONS \\ Stanley S. Glickstein \\ Westinghouse-Bettis Atomic Power Laboratory
}

\begin{abstract}
The mechanisms Involved in arc-weld pool interactions are extremely complex and no complete theory is presently available to describe much of the phenomena observed during welding. For the past several years, experimental and analytical studies have been undertaken at the Bettis Atomic Power Laboratory to increase our basic understanding of the gas tungsten arc welding process. These studies have included experimental spectral analysis of the arc in order to determine arc temperatures, and analytical modeling of the arc and weld puddle. The investigations have been directed toward determining the cause and effects of variations in the energy distribution Incident upon the weldment. In addition, the effect of weld puddle distortion on weld penetration was investigated, and experimental and analytical studies of weld process variables have been undertaken to determine the effects of the variables upon weld penetration and configuration. A review of the results and analysis of these studies are presented.
\end{abstract}




\section{Arc-Weld Pool Interactions}

\section{S. S. Glickstein}

\section{PAGE}

I. Introduction. .............................. 1

II. Arc Studies.................................. 2

III. Heat Transfer............................... 5

IV. Weld Pool Distortion......................... 7

v. Summary and Conclusions........................ 10

References................................. 12

Figures 


\section{Introduction. \\ Gas Tungsten Arc Welding (GTAW) is a process wherein coslescence of}

metal is produced by heating the metal with an arc discharge formed between a tungsten electrode and the workplece. The resultant weld is a product of complex interactions that occur between the electrode, the arc, and the weld pool. A review of the GTAW process was made several years ago by this writer and it was concluded that efforts devoted to improving our understanding of these complex arc-weld pool interactions have found little support in the research and development laboratories in the United States. As a result, a program at the Westinghouse-Bettis Atomic Power Laboratory devoted to fundamental studies of the GTA welding process was initiated. These studies have focused on three major areas of investigation 1) arc physics, 2) weld pool distortion, and 3) heat transfer within the weldment.

While we have tried to analyze each of these areas of concern separately, the interaction between the arc, the weld pool, and the heat transfer mechanisms play a dominant role in the weld process. For example, distortion of the weld pool can affect both the size and shape of the weld. The distortion is a result of arc pressure exerted on the surface of the weldment. This pressure results from a changing arc configuration and is influenced by the thermal and electrical properties of the gas. The properties of the gas are affected by vapor emission frow the surface of the weldment. The type, and rate of vapor emission is determined by the temperature of the weld pool which in turn 18 established by the heat transfer processes within the weldment. In addition, the shape of the electrode has a strong influence on the configuration of the arc discharge. Vapor emission can erode the electrode and thus perturb the shape of the arc. 
These feedback mechanisms between the electrode, the arc, and the we1dment are extremely complex and have yet to be incorporated into a complete analysis. What has been done at this stage of development is to study the arc, weld pool distortions, and the heat transfer process separately. The objective in each of these studies was to establish the important factors that influence the welding process.

The following sections of this paper briefly review and summarize the results of our investigations in these three areas of concern, Details of the scudies can be found in References $1-5$,

\section{Arc Studies}

The size and shape (width/depth) of the weld is strongly dependent upon the magnitude and distribution of the input energy ${ }^{3}$. Because the welding arc is a principle factor in determining the input energy to the weldment, calculationa $1^{4}$ and experimental $1^{1-3}$ studies have been initiated to investigate the properties of a typical welding arc.

Calcularionally, one dimensional axisymetric model of the arc as expressed by the energy conservation equation

$$
\sigma E^{2}-U=-\frac{l}{r} \frac{d}{d r}\left(r K \frac{d T}{d x}\right)
$$

where

$$
\begin{aligned}
& \sigma=\text { electrical conductivity } \\
& K=\text { thermal conductivity } \\
& E=\text { electric field strength } \\
& U=\text { radiated power per unit volume } \\
& r=\text { distance from the axis of the arc } \\
& T=\text { tcmperature }
\end{aligned}
$$

was used to study the radial tempersture distribution as it is effected by the temperature dependent thermal and electrical properties of the gas. In particular, helium, argon, and various mixtures of these gases were investigated. The importance of the temperature distribution resides in the fact 
that once the temperature distribution is known, the current density $f$ can readily be inferred assuming knowledge of the electric field intensity $E_{0}$ This can be obtained from the following equation:

$$
j=\cdots(T) E
$$

From $j$, the energy distribution $\hat{\Xi}(r)$ can be obtained from

$$
\tilde{E}(r)=j(r)\left[v_{a}+k T+w\right]
$$

where

$$
\begin{aligned}
V_{a} & =\text { anode potential drop } \\
k T & =\text { thermal energy in plasma } \\
W & =\text { anode work function }
\end{aligned}
$$

It should be stressed that a one-dimensional analysis represents the effect in the column region of a long arc. The actual input energy at the arc-weldment boundary is complicated by convection and electromagnetic interactions occurring within the arc. It is these interactions at the weldment boundary that have made the development of the welding arc model extremely complex, difficult, and incomplete. Typical temperature and current density distributions for helium, argon, and argon-helium gas mixtures are shown in Figure 1. Unfortunately, under practical welding conditions the arc contains metal vapors emitted from the weldment during the melting of the workpiece. These vapors interact with the "clean" gas environment. The arc analysis has been extended to include the effects of minor addition of aluminum vapor entering an argon helium discharge. The results shown in Figure 2 reveal a significant perturbation of the radial temperature and current density distributions of a helium discharge when a small addition of aluminum vapor is present. These results are a typical representation of any low range ionization potential element such as $\mathrm{Al}, \mathrm{Fe}, \mathrm{Ni}$, or $\mathrm{Cr}$, etc. in helium, whose ionization potential is $24.46 \mathrm{eV}$. For argon whose ionization potential is $15.08 \mathrm{eV}$, the effect of impurity contamination due to these lower ionization potential elements is less significant. 
Also studied experimentally and analytically were shielding gases containing mixtures of argon and helium. The results show that less than $1 \%$ addition of argon gas significantly perturbs a pure helium discharge, while small additions of helium to an argon discharge have little effect on the arc configuration. Measurements of the electric field and analysis of the potential drop associated with each gas indicate that the greater energy of a helium welding arc compared to argon can be attributed to a larger anode drop potential in helium relative to argon. This accounts for the 80 called "hotter" axc of helium and is not due to the higher arc remperature of the helium discharge as is comonly belleved.

The electric field and configuration of the arc are also influenced by the shape of the electrode tip in the GTA welding process. Vapor emission from the weldment can interact with the electrode causing erosion of the tip ${ }^{6}$, thus perturbing the arc discharge.

Although these arc studies have emphast zed the effects of minor contaminants in the welding gas and their effect on arc configuration, minor elements in the weldment can oignificantly affect weld penetration through other type interactions that have been discussed elsewhere ${ }^{6}$.

While radiation from the welding arc contributes a negligible amount of energy to the weldment, it is an important factor in the energy conservation equation for an argon arc with temperatures greater than $10000 \mathrm{~K}$. The analytical studies clearly revealed that radiation $1088 \mathrm{~s}$ for a $100 \mathrm{~A}$ arc cannot be considered negligible. These losses reduce the peak temperature along the arc axis and broaden the radial temperature distribution, thus influencing the energy distribution.

An important factor controling the rate of vapor emission into the arc from the surface of the weldment is the heat transfer mechanism within the weldment. In order to understand the important factors that influence heat transfer, calculational and experimental studies were initiated. The results of these investigations are discussed in the next section. 


\section{Heat Transfer}

Variations in the input energy distribution at the surface of the weldment can be attributed to the arc-weld pool interaction such as explained previously in the axc analysis. The consequences of such variations have been studied analytically ${ }^{3}$ using a heat transfer model and the finite element method for calculating the transient temperature, stress, and distortion resulting frow the welding process.

Briefly, the energy input from the welding arc is assumed deposited on the surface of the weldment as a radially symetric normal distribution function. Heat flow is assumed axisymetric about the center of the heat source. A unique feature of the model is the inclusion of phase change effects such that latent heat is absorbed during melting and liberated during solidification of the weld metal.

Temperature-dependent specific heat and thermal conductivity are employed, and surface heat $1088 e s$ due to convection and radiation are included in the model. Temperature transients were calculated and compared to experimentally measured values at discrete polnts on the weldment. Typical results are shown in Figure 3. Such comparisons permit an evaluation of the strength of the hest source $Q_{0}$, and an estimation of the weld process effictency $\eta$ given by

$$
\eta=\frac{Q_{0}}{\nabla I}
$$

where

$$
\begin{aligned}
& Q_{0}=\text { strength of heat source } \\
& V=\text { welding arc voltage } \\
& I \text { - welding current }
\end{aligned}
$$


The analytical and experimental investigation of the welding thermal cycle for stationary gas-tungsten arc welds led to the following conclusions:

1. The welding thermal conduction analysis produces a thermal cycle that is in very good agreement with thermocouple data at locations outside the weld metal and heat-affected zones.

2. Though calculated depth of penetration of the weld was in line with depths measured from metallographic sections, the humped, shallow weld metal configuration observed for stationary test welds could not be reproduced analytically. Introduction of anisotropy of the effective weld pool conductivity, though producing a more shallow weld bead, resulted in bead dimensions that are smaller than the measured values.

3. The nature of the weldment thermal response and the resulting weld bead penetration and shape characteristics were very much dependent on the thickness of the weldment relative to the heat input from the arc. The differentiation between "thin" and "thick" weldment types of thermal response is crucial for proper interpretation of any experimental or analytical welding analysis. When attempting to identity certeain characteristics of a welded joint by performing bead-on-plate welds, the thickness of the test weld must be compatible with the actual thickness of the weldment for which the test results are to be applied.

4. The analytical model demonstrated that, for a weld whose depth of penetration is as low as $60 \%$ of the thickness, a small increase in current can produce a full-penetration weld.

5. In addition to the magnitude of the heat input from the welding arc, the area over which that heat 18 distributed on the weldment surface is an additional parameter that strongly influences penetration and weld bead shape characteristics. 
6. The finite element welding thermal analysis method is very well sulted for determining the interrelationship of heat input magnitude, heat input distribution, duration of the heat input, and weldment geometry on the thermal response. In particular, it can be used for calculating that combination of thermal and geometric parameters that will produce an optimum weld configuration for a given joint.

7. Though the means have been established to specify magnitude and distribution of the heat input from the arc so that an optimum weld metal configuration and weldment thermal response will be obtained, the problem remains $a 8$ to how these parameters may be controlled by varying specific welding parameters such as current, voltage, electrode shape, arc gap, shielding gas, and insert additives. The previous discussion of the arc studies attempted to direct itself to the effects of various shielding gases and impruities in the arc on just this problem.

As a result of this study on heat transfer within the weldment, it was concluded that heat transfer exclusively by conduction is inadequate to completely characterize thermal conditions in the weld puddle. To accurately predict both depth of penetration and width of the weld metal cross-section, work on weld pool heat transfer, as well as effects of weld pool distortion need to be considered. Distortion of the weld pool is affected by the configuration of the arc. The results of an analytical study which investigated the effects of weld pool distortion on weld penetration is discussed in the next section.

\section{Weld Pool Distortion}

The change in the radial current density distribution along the axis of the welding arc coupled with the electromagnetic interaction induces the so called "arc jet". This phenomenon had been discussed and explained in detail by Finkelnburg and Maecker ${ }^{7}$ many years ago. The effect of the arc fet is to distort the surface of the weld puddle as shown for example in Figure 4. 
An analytical model has been developed by Friedman ${ }^{5}$ using the finite element method of analysis, and considers both heat flow in the weldment and changes in pool shape due to both the arc jet and gravitational forces.

The heat supplied by the arc is conducted through the weldment in its distorted configuration. Under the action of the arc pressure and gravitational forces, the heated surface of the weld puddle in the vicinity of the weld centerline is depressed below its original elevation as shown by the distorted finite element grid in Figure 4. It is this depression that significantly affects the penetration characteristics of the weld. Calculations were carried out in increments of time, so that weld puddle distortion progressed in discrete steps, rather than continuously. The distortion of the molten surface is inhibited by the surface tension existing at the interface between the puddle and atmosphere. In the analytical model, it is simulated by a membrane with uniform isotropic tension. The pressure supplied by the arc to the surface of the weldment is taken to be distributed as a radially symmetric normal distribution function.

The effects of arc pressure and gravity forces on penetration and weld bead dimensions are illustrated by determining the growth of the weld pool with time neglecting pool distortion (1.e., neglecting arc pressure and gravity forces or assuming very large surface tension), and then comparing the results with those obtained using representative pool distortion parameters.

The reaults plotted in Figure 5 show that the distortion of the pool contributes significantly to the penetration characteristics of the weld especially when the depth of penetration approaches the weldment thickness. When including the effects of puddle distortion due to arc pressure and 
gravity forces, full penetration occurs after 32 of heating; neglecting pool distortion, full penetration is not yet attained at $40 \mathrm{~s}$.

The maximum arc pressure resulting from electromgnetic forces is proportional to the square of the current. It is thus of interest to determine the effects of arc pressure on the growth and penetration of the weld puddle. (Although an increase in current produces increases in both heat input and arc pressure, only the latter is considered here).

The results are presented in Figure 6 , in which the growth of the pool dimensions with time is plotted for a number of values of the maximum arc pressure. Figure 6 also demonstrates that arc pressure significantly influences weld penetration when the puddle penetrates to approximately 60 percent of the weldment thickness. For these penetrations, the depression of the heated surface of the pool is of sufficient magnitude that the rate of further fenetration depends strongly on the degree to which the surface is depressed. The effect on bead width (at the heated (top) surface) is less pronounced, since the influence of pool depression on the radial transfer of heat in the weldment is less than on the heat transfer through the thickness.

From this study, the following was concluded:

1. Distortion of the weld pool contributes significantly to the penetration characteristics of the weld, and the propensity of a weld bead to fully penetrate the thickness of the weldment is enhanced by weld pool depression.

2. Arc current influences weld penetration from two standpoints: (a) Increased current results in more heat input from the arc to the workpiece, causing more material to be melted; and (b) arc pressure increases 
with the square of the arc current, producing a greater degree of pool depression. Application of heat at surfaces beneath the undistorted surface of the weld further enhances penetration. Penetration becomes sensitive to small changes in current when the depth of the pool exceeds 60 percent of the weldment thickness.

3. For partial penetration welds, depression of the top surface of the weld pool varies linearly with arc pressure. When full penetration is ạchieved, weld bead shape changes are significantly more sensitive to changes in pressure.

4. Both pool depression and weld penetration are strongly dependent on surface tension at the puddle surfaces. The understanding and controlling of surface tension is essential to controlling weld pool shape change, as well as enhancing penetration. But surface tension can be affected by minor elements in the weldment as well as the temperature of the weld pool. Thus, the need for an accurate heat transfer model is again emphasized.

\section{Summary and Conclusions}

In order to improve our current understanding of the arc-weld pool interactions that occur during the GTAW process, experimental and analytical studies of the welding arc and heat transfer process have been performed. Temperature in arcs and metal vapor emission from the weld pool produced under typical welding conditions were Investigated spectroscopically. This information has provided a basis for comparing experimental results with those of simplified analysis of the arc discharge. The present analysis employs a one-dimensional model of the welding arc that considered heat generation by the Joule effect and heat losses by radiation and conduction. It has been used to study the effects of various gases and gas mixtures currently employed for welding applications. Minor 
additions of low ionization potential impurities to these gases have been shown to significantly perturb the electrical properties of the parent gas causing gross changes in the radial temperature distribution. of the arc discharge. Such changes are reflected in the current density distribution, input energy distribution of the weldment, and ultimately in weld penetration and configuration.

One of the more important arc-weld pool interactions is the distortions of the weld puddle due to pressure from the weld arc, and inherent changes in weldment heat transfer that accompany such distortion. An analysis of weld pool distortion which treats the effect of arc pressure and surface tension on the pool configuration has recently been completed. The results of this study has significantly contributed to our understanding of how welding parameters influence weld penetration and configuration.

Variations ir input energy distribution to the weldment that may occur due to arc perturbations have been input to an analytical model developed for calculating transient temperatures, stresses, and distortions resulting from the welding process. Verification of the thermomech anical analysis has been achieved through experimental studies. An in-depth analytical investigation has also been performed to study the effects of varying a number of welding parameters on the thermal response of the weldment.

While each of these studies have been treated separately, it has been stressed repeatedly that the interaction between the arc, the surface of the pool, and the heat transfer mechanisms are intertwined such that each study is strongly influenced by the other. In addition, the important role of weld pool motion has been omitted at this stage of development. It too must be considered as a major parameter in establishing the 


$$
-12-
$$

the solidification pattern of the weld pool. In the future, more effort must also be directed toward incorporating into the analysis the complex feedback mechanisms that have been discussed in this paper.

\section{References}

1. S. S. Glickstein, E. Friedman and W. Yeniscavich, "Investigation of Alloy 600 Welding Parameters," Weld. J., 54, Res, Suppl. 113-S, April 1975

2. S. S. Glickstein, "Temperature Measurements in a Free Burning Arc," Weld. J., 55, Res. Suppl., 222-S, August 1976

3. E. Friedman, and S. S. Glickstein, "An Investigation of the Thermal Response of Stationary Gas Tungsten-Arc Welds, "Weld. J., 55, Res. Supp1. 408-S, December 1976

4. S. S. Glickstein, "Arc Modeling For Welding Analysis," WAPD-TM1382, April 1978

5. E. Friedman, "Analysis of Weld Puddle Distortion and Its Effect on Penetration," Weld. J., 57, Res. Supp1. June 1978

6. S. S. Glickstein and W. Yeniscavich, "A Review of Minor Element Effects on the Welding Arc and Weld Penetration." Weld. Res. Cuunc11, Bullet1n No. 226, May 1977

7. W. Finkelnberg and H. Maecker, "Elektrische Bögen und Thermisches Plasma, Handbook der Physik, Bd XXII (Springer-Verlag, Berlin 1956), 254, English Translation: ARL 62-302 (1962) 


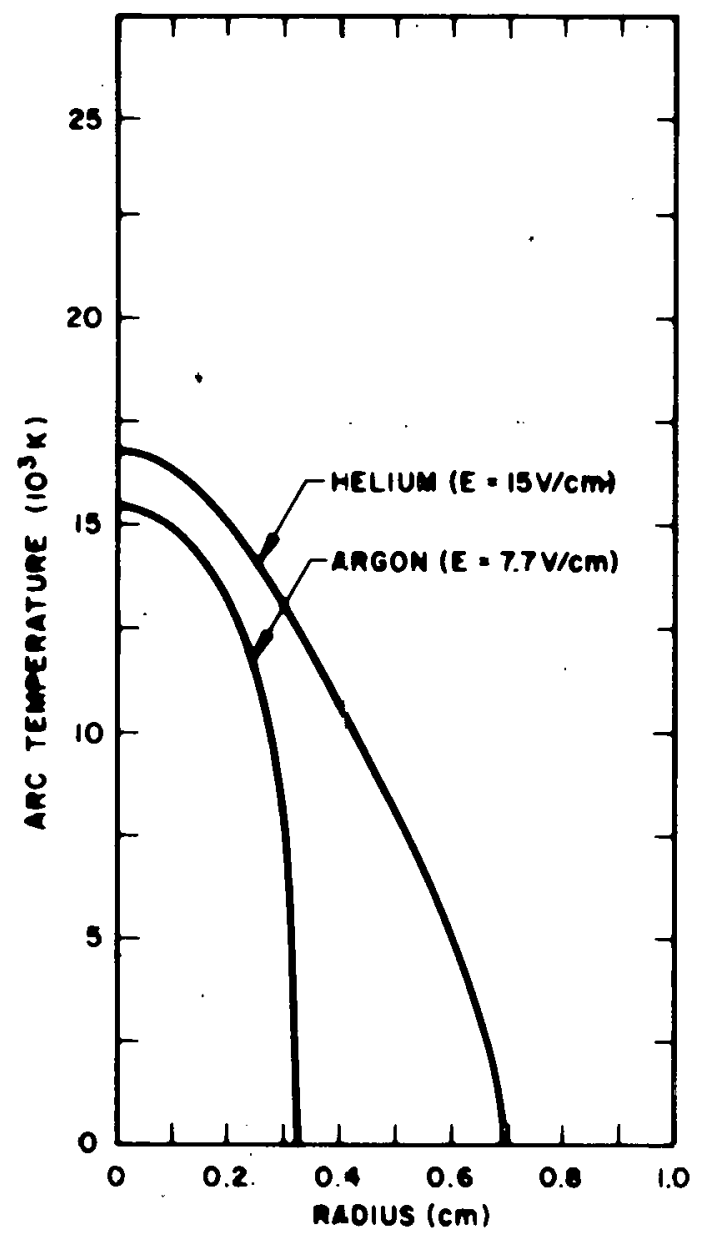

(a)

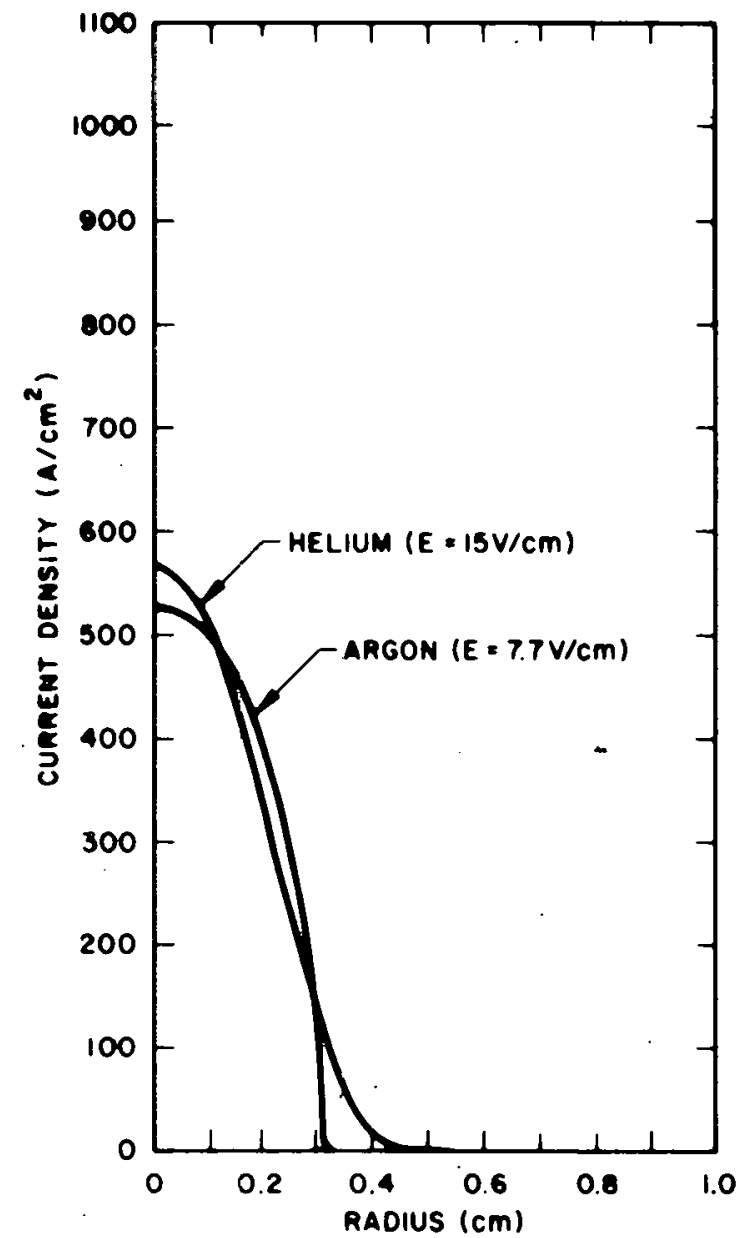

(b)

Pigure 1 - Radial Temperature and Current Density Distributions for Fure Helium and Argon Arcs. I $=100$ amps

a) Temperature Distribution b) Current Density Distribution 


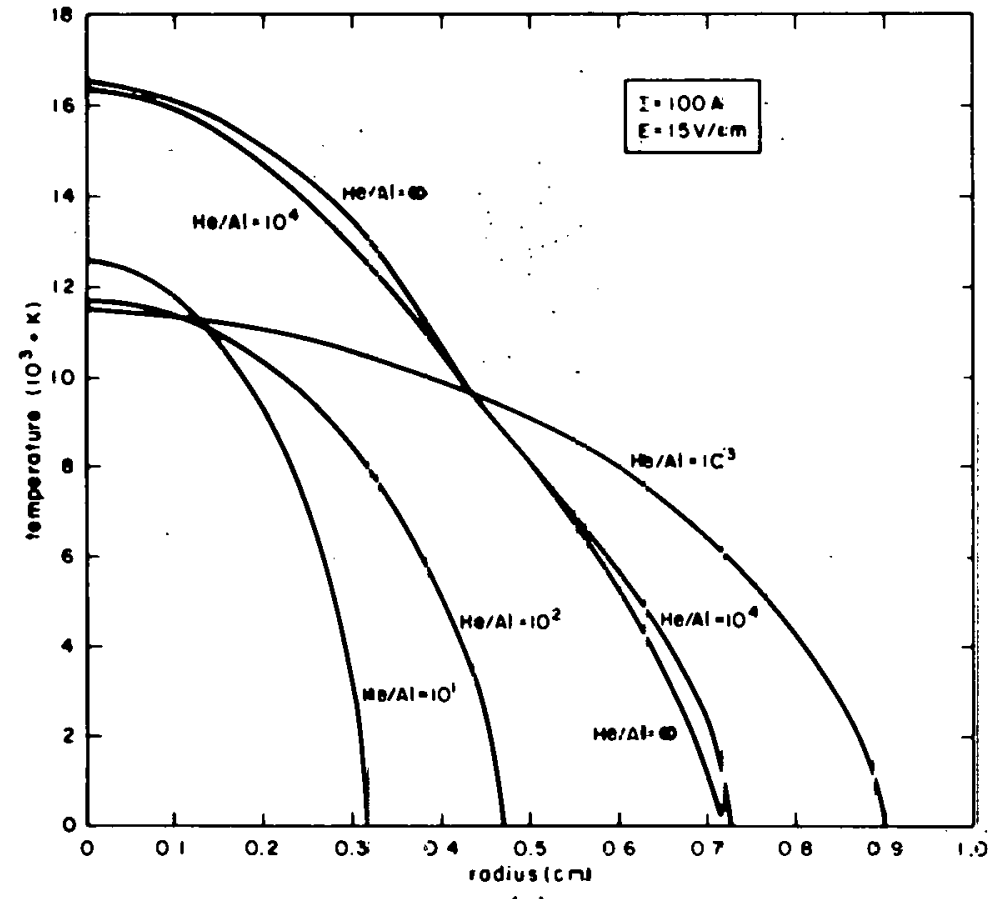

(o)

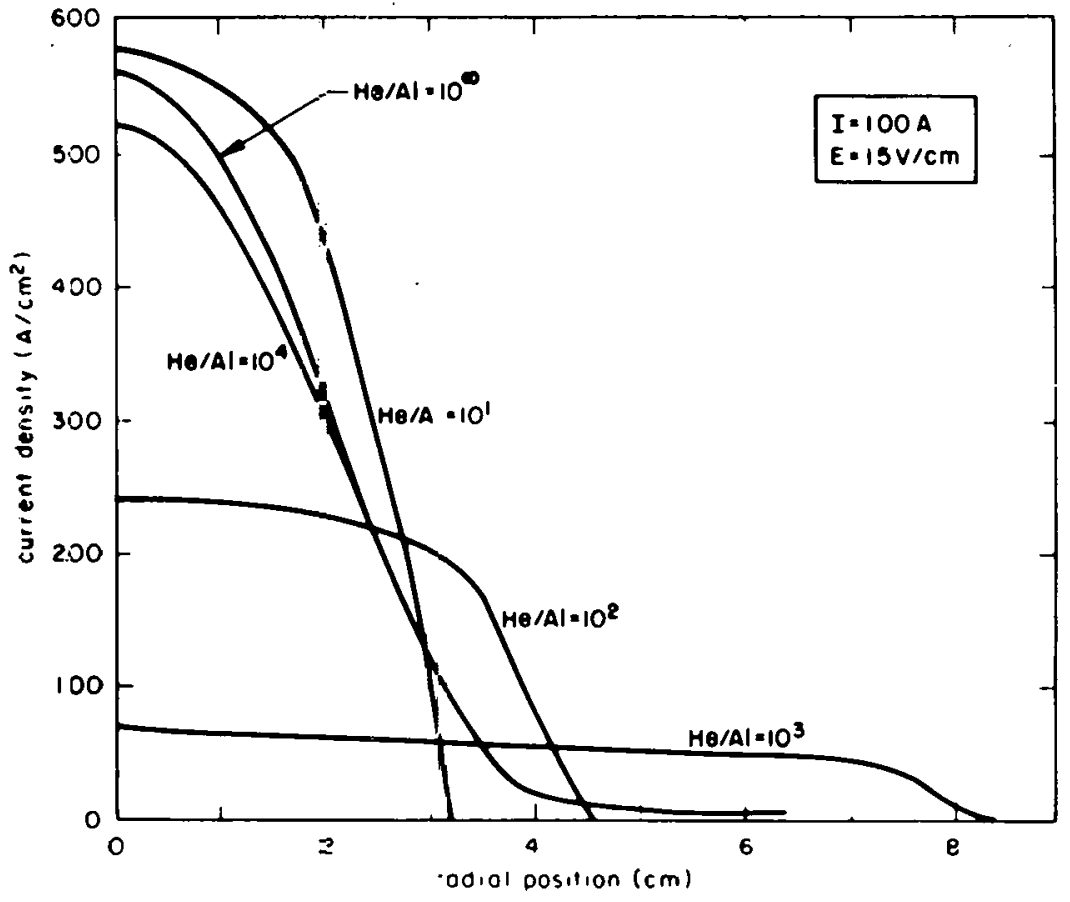

(b)

Figure 2 - Radial Temperature and Current Density Distributions for Verious Mixtures of Aluminum and Helium Gas.

a) Temperature Distribution b) Current Density Distribution 


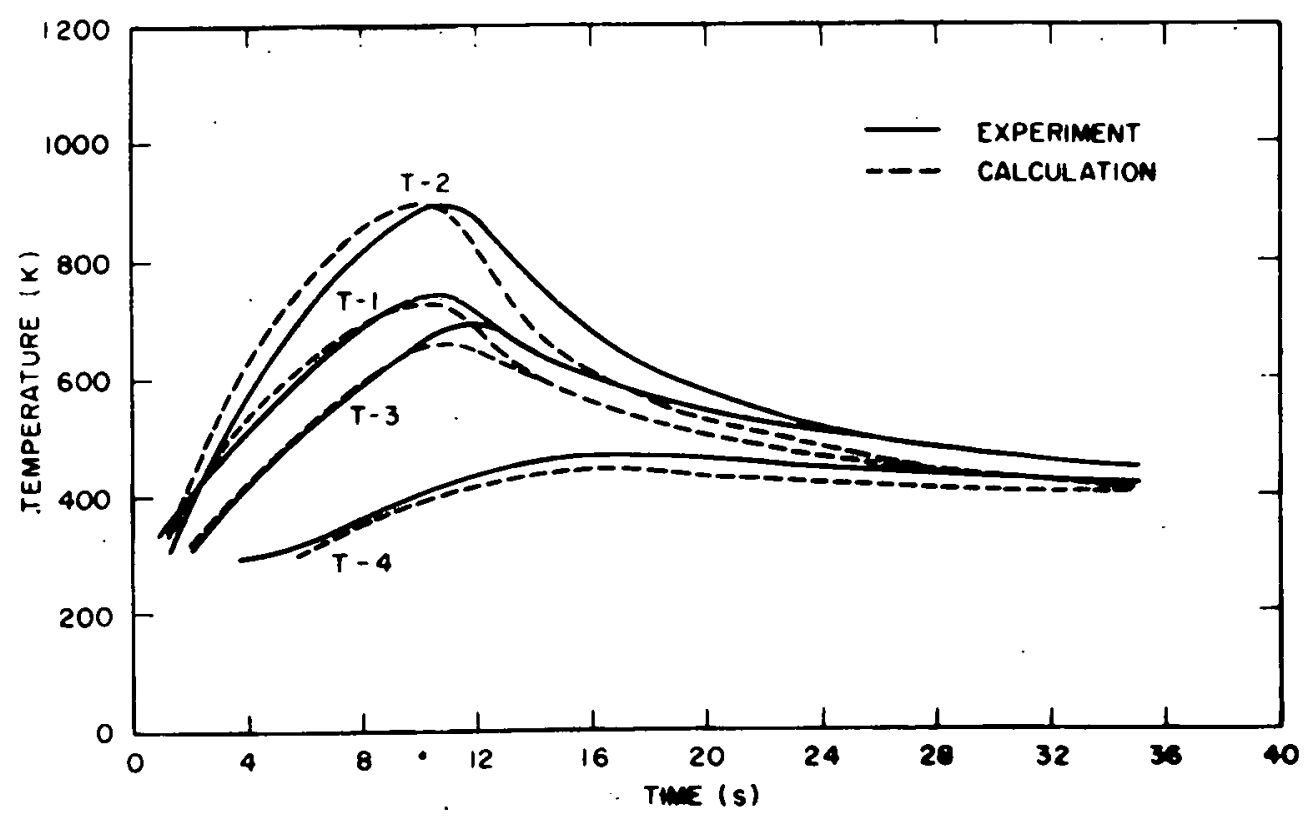

Figure 3 - Comparison Between Calculated and.Experimental Transient Temperature Response at Four Thermocouple Positions $I=90 \mathrm{~A}$, $v_{\text {a }}=7.7, V$ Arc Gap $=0.76 \mathrm{~mm}$

Weld Time $=10 \mathrm{~s}, Q_{0}=530 . \mathrm{W}, \overline{\mathrm{r}}-3.81 \mathrm{~mm}$

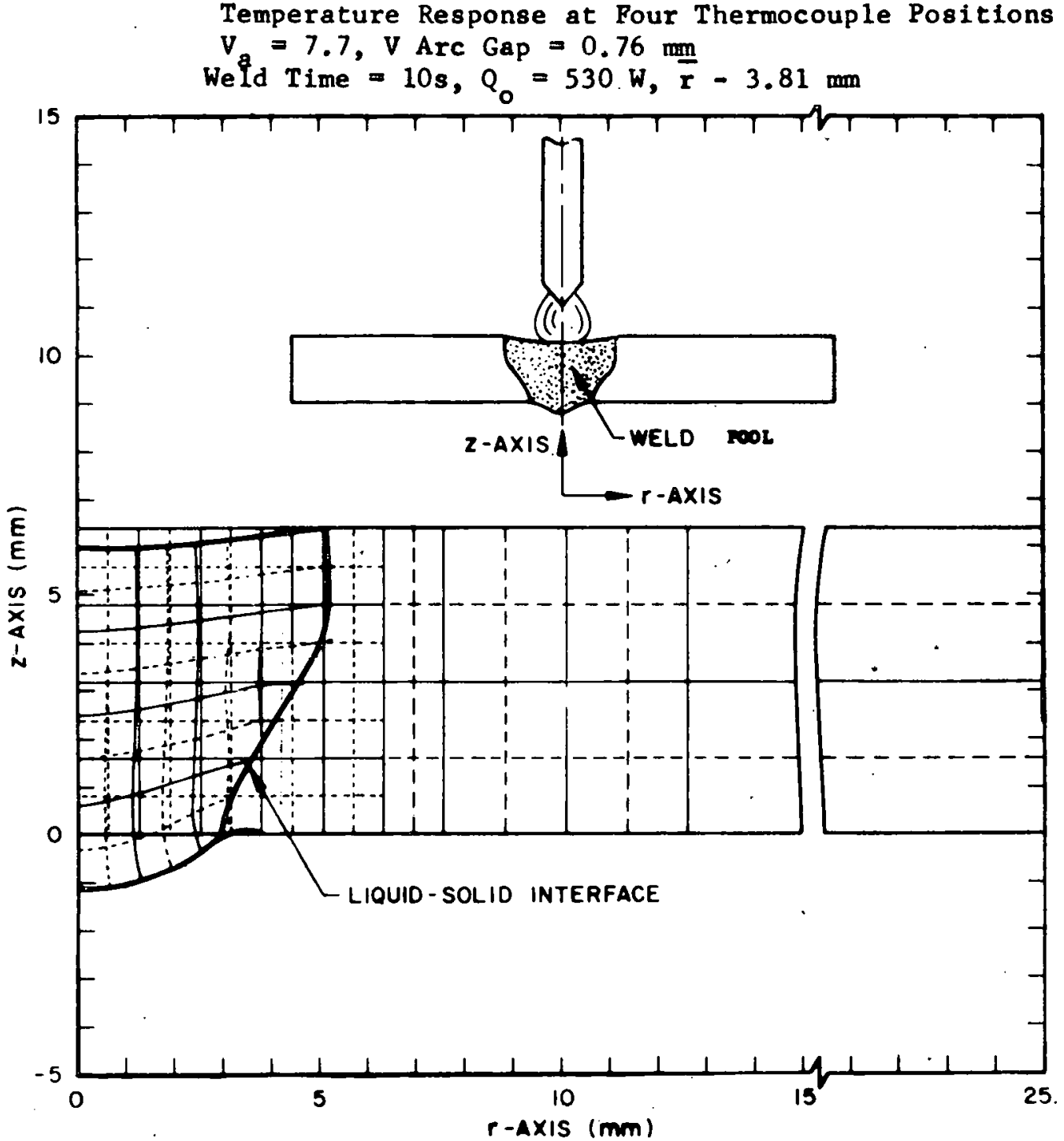

Figure 4 - Weld Bead Distortion As Depicted By Deformed Finite Element Mesh 


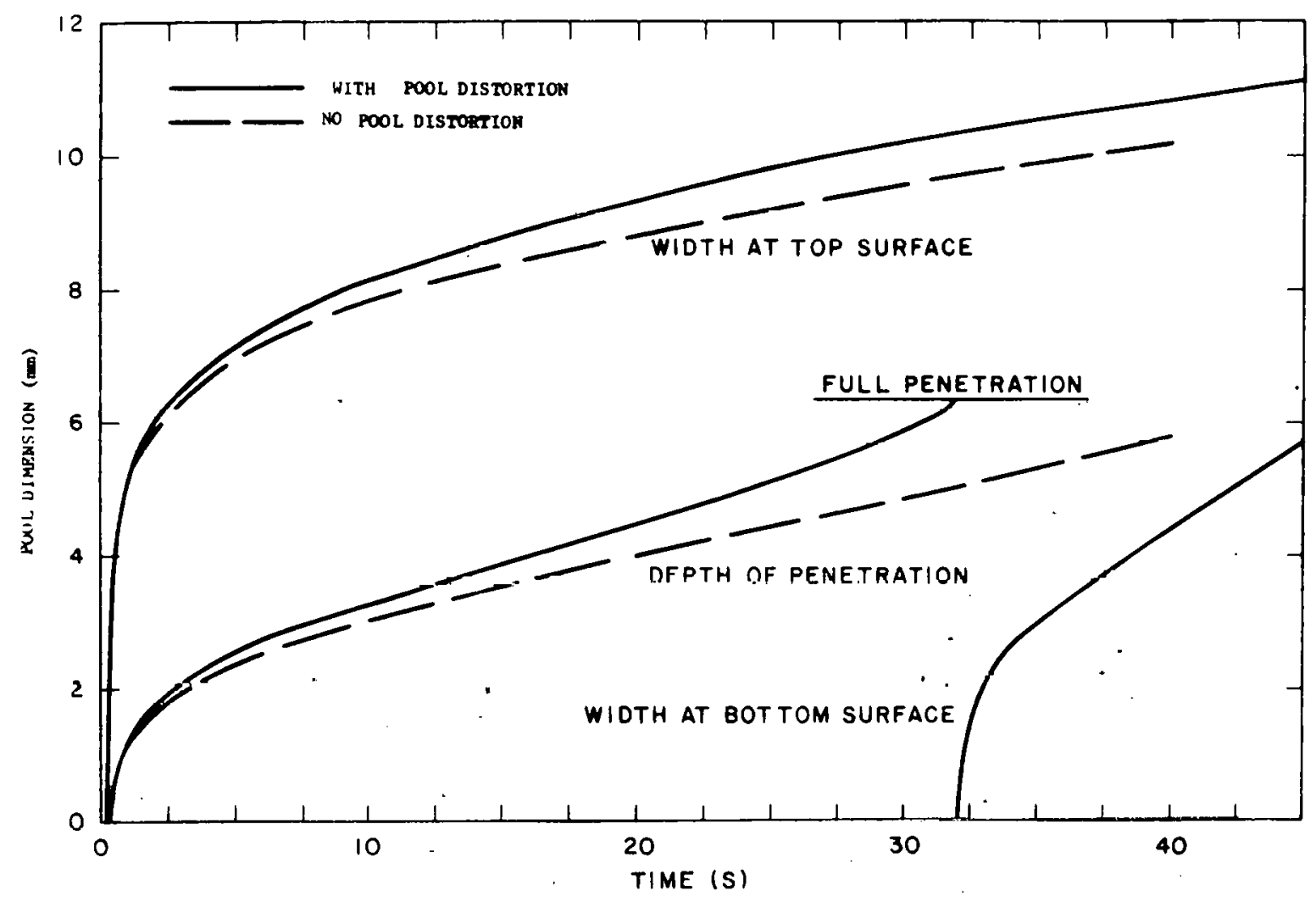

Figure 5 - Effect of Pool Distortion on Pool Dimensions. Pressure $=1000 \mathrm{~Pa}$.

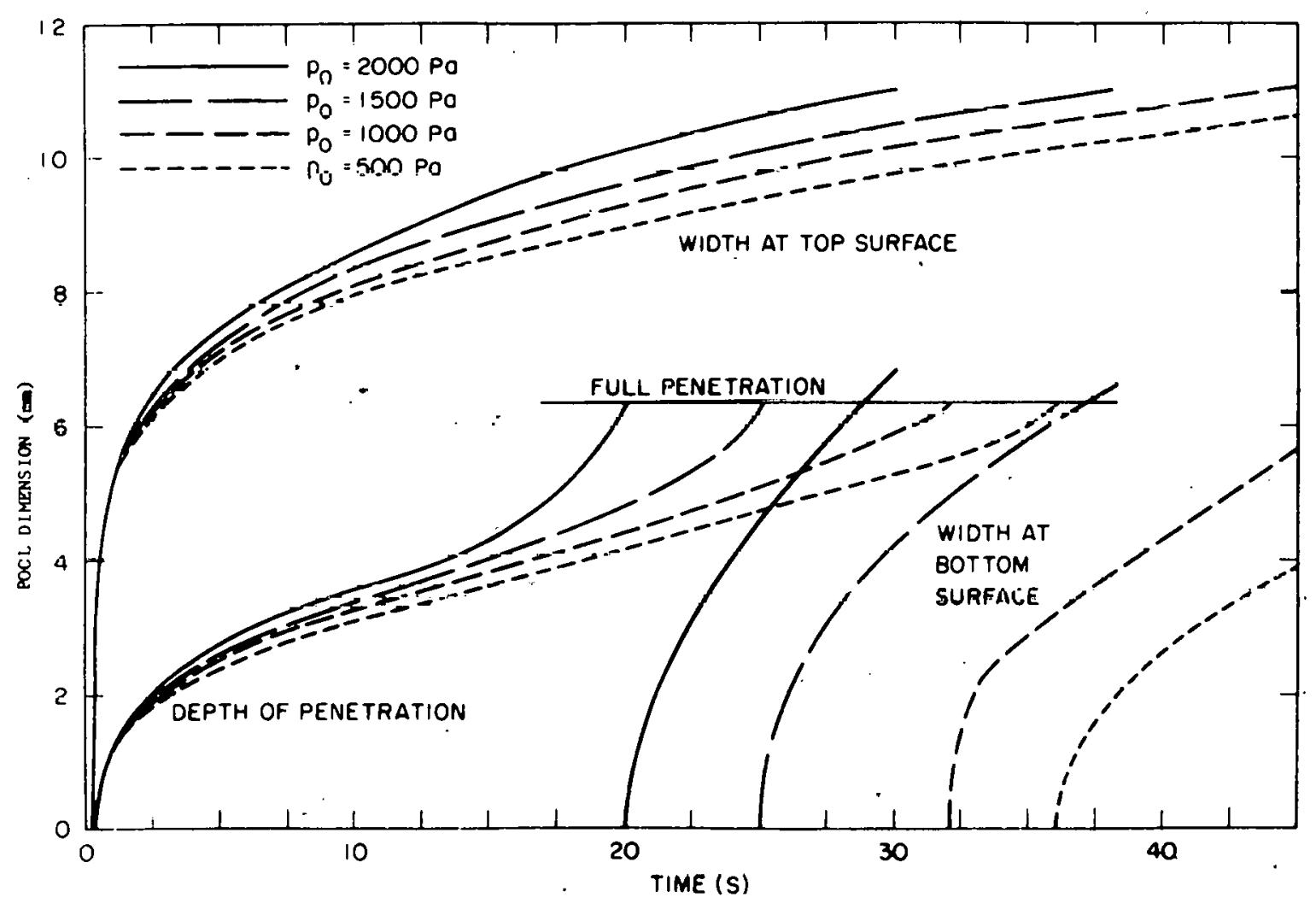

DU.S. GOVERNMENT PRINTING OFFICE: 1978-703-115/854

Figure 6 - Effect of Arc Pressure On Pool Dimensions 